\section{Determinant of contemporary society?}

Nuclear Power for Beginners, Including the Alternatives. By Stephen Croall and Kaianders Sempler. Pp.176. (Beginners Books/Writers and Readers Publishing Cooperative: London, 1979.) Hardback £3.50; paperback £1.80.

"NuClear power is complicated, but not that complicated. The basics are fairly simple. Anyway it's not just a question of techniques or economics. It's about the kind of society we want for ourselves and future generations".

It really is strange the way nuclear power is inflated into the position of being a determinant of the evolution of contemporary society. It is seen by those for it and against it as having an almost mythical power to influence the totality of social activity; far beyond that of much more pervasive influences such as the telephone or the motor industry.

This, of course, is not the issue addressed in this book. The twin hypotheses on which it rests are that nuclear power does determine the future of society; and for the worse. Accepting these for the moment it is interesting to see the way the case is developed. The format is that of a lurid comic book. There are plenty of death's heads, bombs, and King Kong multinational companies trampling the populous underfoot. Civil nuclear power is tied up in the same package as nuclear warfare, imperialism, reckless and wanton abuse of the environment, and a suicidal disregard for the future of the human race.

It is very well done. The text and pictures are humorous and compelling; the reader is pulled through the book quite effortlessly. The amount of information conveyed is quite remarkable, as is the level of its sophistication. As an exercise in communication it succeeds very well indeed. What it communicates is, of course, another question entirely. There is not the slightest attempt to be balanced or objective. And there is the crux of the nuclear argument. It is too seldom about nuclear power.

The alternative vision of society here is based on the proposition that the 'Soft Energy Path' of Amory Lovins is a proven alternative. China of the Cultural Revolution is said to have "come closest to the soft energy model"'. If true, so much the worse for soft energy. The details of the Chinese experience in the 1966-76 decade are emerging. They show that behind the rhetoric of participation, people's democracy, and self-help was a reality of anarchic arbitration, oppression, and waste of resources which brought the country to the brink of collapse. If the country was a "display window for alternative ecologically viable techniques" then it showed they bring a crop of problems as grave as those they were meant to solve.

It is not to say that there is no valid point to be drawn from this book; the pity is that the nuclear debate has to be conducted so often on the basis of conflicting rhetorics and hyperbolic pretensions. For every fantasy on the anti-nuclear side there is one on the pro-nuclear side. Evasions, halftruths, and downright lies litter that side of the debate too.

In the full picture of the world's energy needs nuclear power is not very important. But it can have its uses. It should take its place in the array of choice facing society - to be assessed on its merits, and dangers, against the alternatives. But in the context of all the pressures which create the "kind of society" we are passing on to future generations nuclear power is a minor

\section{Electricity harnessed}

Electricity from Glass: The History of the Frictional Electrical Machines, 1600-1850. By W.D. Hackman. Pp.310. (SijthoffNoordhoff: The Netherlands, 1978.) $\$ 44.50$.

THIS is a very welcome book - for what it provides, what it suggests and what it makes possible.

What it provides is a classification scheme and history of frictional electrostatic machines, devices which constituted the first important electrical invention. Together with the Leyden jar, they made possible, by the 1840 s, production, storage and discharge of substantial quantities of electricity. Hackman's classification is by critical physical factors: globe versus cylinder versus plate; horizontal versus vertical axis; single versus multiple elements. Such an approach is convenient for the person who has a machine which needs to be identified; and it is reasonable historically, as many of the features were seen as improvements which were adopted and which superseded previous designs.

The suggestion is that these machines were important, as surely they were. With the more impressive effects now available, electricity moved out of its infancy into the realm of fully fledged science. Experiments no longer consisted of rubbing glass tubes and picking up bits of paper. They included sparks several inches long and discharges strong enough to knock a man senseless. Entirely new categories of tests could be performed, with new theoretical structures to match them. One clear result was the pioneering work of Benjamin Franklin, who began his investigations just as the new apparatus was being introduced. He was thus confronted almost immediately with element. The passionate arguments that occur both for and against nuclear power are a diversion from much more serious topics.

For its merits as a piece of propaganda, and its enrichment of the fantasy world of nuclear power this book deserves its place on the bookshelf with all those other books of dreams which began with a vision of electricity so cheap it would not be worth the expense of metering. The point is becoming clearer every day: both sides expected too much from nuclear power. It is neither as bad as those who were driven to produce this book feared, nor as great a boon as those in favour of it believed it was going to be. It is time the argument moved on.

Gerald Foley

Gerald Foley is a Fellow of the International Institute for Environment and Development, London, UK.

the need to explain sparks and shocks and induction, and he bypassed the more subtle phenomenon of electrostatic attraction which had dominated the thinking of his contemporaries who had come on the scene slightly earlier. The former line of attack proved fruitful, the latter was a dead end. Furthermore, the impressiveness of the effects made them valuable as educational tools, increasing the interest of the public and of students in electrical phenomena. Investigators were quick to seize the opportunity, and some were giving accounts of impressive demonstrations.

The book makes possible the beginnings of a systematic catalogue of a surprisingly large number of objects, and it is reasonable to presume that by bringing together information about a substantial portion of them we could gain considerable insight into the interactions among instrument makers, and the interdependence of theory and practice during the early years of an important discipline.

For this reason, it would have been a great help if the number of photographs had been increased - by a factor of two or three at least, over the thirty-four presently included - and if more attention had been paid to the quality of reproduction. Also desirable - though this would probably demand a new research project - would be the sort of details one usually finds in museum catalogues: critical dimensions, chemical analyses and descriptions of construction materials.

The book is certain to encourage many people to look at their electrical machines with new understanding. Inevitably, it will stimulate the accumulation of further information and lead us into a better understanding of the origins of electricity as an experimental science.

Bernard S. Finn

Bernard S. Finn is at the Smithsonian Institution, Washington, DC. 